\title{
Performed Eligibility Criterion
}

National Cancer Institute

\section{Source}

National Cancer Institute. Performed Eligibility Criterion. NCI Thesaurus. Code C93366.

One of a set of conditions that a study subject must meet in order to participate in a study. 